\title{
Los derechos colectivos del trabajo doméstico en relación con el Estatuto de los Trabajadores
}

The collective rights of domestic work in relation to the Workers' Statute

CONCEPCIÓN SANZ SÁEZ

Universidad de Castilla La Mancha, España

\section{Resumen:}

El reconocimiento de los derechos colectivos para las personas trabajadoras del servicio doméstico viene dado por el artículo 2.2 del Estatuto de los Trabajadores, así como por el silencio del Decreto 1620/2011, de 14 de noviembre, por el que se regula la relación laboral de carácter especial del servicio del hogar familiar que supone la aplicación supletoria de la normativa laboral común, compatible con las peculiaridades de la relación laboral especial, como ya señalaba la legislación anterior en el Real Decreto 1424/1985 de 1 de agosto.

Esta particularidad produce que el ejercicio de derechos colectivos por estas personas sea escaso, no porque el ordenamiento jurídico lo prohíba, que no lo hace, sino porque las dificultades para su ejercicio no han sido resueltas por la norma reglamentaria.

Palabras clave: Trabajo doméstico, derechos colectivos, Estatuto de los Trabajadores.

\begin{abstract}
:
The recognition of collective rights for domestic workers is given by article 2.2 of the Workers' Statute, as well as by the silence of Decree 1620/2011, of November 14, which regulates the employment relationship of a special nature of the family home service, which implies the supplementary application of the common labor regulations, compatible with the peculiarities of the special employment relationship, as already indicated by the previous legislation in Royal Decree 1424 / 1985 of August 1.

This particularity causes that the exercise of collective rights by this group is scarce, not because the legal system prohibits it, which it does not do, but because the difficulties for its exercise have not been resolved by the regulatory norm.
\end{abstract}

Keywords: Domestic work, collective rights, Workers' Statute.

\footnotetext{
Correspondencia a:

Concepción Sanz Sáez, Rda. Del Parque, 28 bajo A, Ciudad Real, (Castilla La Mancha), España.

Email: concepcion.sanz@uclm.es -ORCID: https://orcid.org/0000-0001-9783-9272

Recibido: 13-05-2021; aceptado: 03-06-2021.

ISSN 1575-7048 - eISSN 2444-5819 / ๔ 2021 UPV/EHU

(c) (1) 2021 CC BY Autor/a o Autores/as y UPV/EHU Press
} 


\section{El Estatuto de los Trabajadores como punto de partida en el desarrollo infraconstitucional del trabajo doméstico}

La Ley 8/1980 de 10 de marzo del Estatuto de los Trabajadores (en adelante ET), si bien unifica la legislación laboral en una norma base y de derecho necesario al tener rango de ley, tiene en la práctica efectos muy significativos, ya que su artículo $2.1 \mathrm{~b}$ ) regulaba el servicio doméstico como una relación de trabajo de carácter especial ${ }^{1}$, estableciéndose en su Disposición Adicional Segunda, la necesidad de desarrollo reglamentario, pero dicha inclusión no fue efectiva hasta la modificación de dicho Estatuto, y considerarse en el citado artículo 2.1 b), relación laboral de carácter especial la del servicio del hogar familiar, estableciéndose en la disposición adicional primera de la ley 32/1984, de 2 de agosto, sobre modificación de determinados artículos del $\mathrm{ET}^{2}$, como el Gobierno, en el plazo máximo de doce meses, contados a partir de la entrada en vigor de la referenciada ley, tendría que regular el régimen jurídico de las relaciones laborales de carácter especial previstas en dicho Estatuto.

Aunque el plazo para el Gobierno era de doce meses, hubo que esperar a la llegada de la promulgación del Real Decreto 1424/1985 de 1 de agosto, donde se regulaba la relación laboral de carácter especial del Servicio del Hogar Familiar (en adelante RLESD). Mediante esta norma se daba cumplimiento al mandato del ET, teniendo en cuenta la necesidad de conciliar la equiparación de las condiciones de trabajo de este colectivo al resto de personas trabajadoras y la consideración de las peculiaridades que se derivan de una actividad prestada en el ámbito del hogar familiar.

\subsection{Las relaciones laborales de carácter especial en nuestro sistema de relaciones laborales}

El artículo 2.1 del ET nos revela que están reguladas por su normativa específica con sus propias particularidades, pero el ordenamiento laboral español no nos ofrece una definición exhaustiva de lo que debemos entender por relación laboral especial, obstáculo que salvamos con la incorporación de las aportaciones doctrinales que analizan los criterios que fundamentan la existencia de relaciones laborales especiales, como el tipo de actividad o la forma en que se realiza, la cualidad de los sujetos que intervienen en la relación laboral, el lugar donde se realiza la actividad , la atenuación de la subordinación o, la que justifica la especialidad en la existencia en el contrato de una causa mixta, con lo que el legislador pretende proteger otros intereses dignos de tutela junto a los laborales.

La inaplicación del ET a las personas trabajadoras con relación especial, que se desprende de su artículo 2.2 tiene como consecuencia la existencia de regímenes jurídicos diferenciados del que establece la norma estatutaria para la persona trabajadora común, lo que plantea la duda sobre si tal distinción vulnera el derecho a la igualdad establecido en la CE.

\footnotetext{
1 La Ley de Relaciones Laborales 16/1976 de 8 de abril, BOE del 21, introduce por primera vez en el ordenamiento laboral español el concepto de relaciones laborales de carácter especial en su artículo 3.1.a) "Son relaciones laborales de carácter especial...: a) El trabajo al servicio del hogar familiar, en sus diversas modalidades”. Si bien la efectividad de esta inclusión quedó suspendida hasta la promulgación de su normativa específica por Decreto del Gobierno de obligatoria aparición en el plazo de dos años a partir de la publicación de la ley, normativa que nunca llego a promulgarse.

${ }^{2}$ La DA $1^{\text {a }}$ de la Ley 32/1984, de 2 de agosto estableció el carácter especial de la relación de servicio del hogar familiar y su regulación se llevó a cabo, primeramente, mediante el Real Decreto 1424/1985, de 1 de agosto. En la actualidad, dicha norma ha sido sustituida por el RD 1620/2011 de 14 de noviembre.
} 
La constitucionalidad del tratamiento legal diferenciado ha sido resuelta por el Tribunal Constitucional, considerando la inexistencia de tratamiento discriminatorio al hallarse su justificación en las especiales características de los trabajos que contemplan, como se desprende de su sentencia 56/1988 de 24 de marzo, donde resuelve que "siempre que ello esté justificado por las características especiales de cada tipo de trabajo” no será contraria al art. 14 de la Constitución.

Ante esta afirmación, no obstante, lo que podemos apreciar en la normativa reglamentaria específica de cada relación laboral especial y de la aplicación del ordenamiento laboral común, es que cuanto mayor aplicación existe de éste, mayor equiparación encontramos entre trabajador/a común y especial y, por tanto, equiparación en la protección siempre que utilicemos como modelo la que prevé el ordenamiento laboral común. Y a la inversa, como es lógico, de la menor aplicación del ordenamiento laboral común se puede inferir una menor protección de la relación especial a la que se le aplica.

Y este alegato, también se alcanza al comprobar cómo doctrinalmente se admite que el régimen de las relaciones especiales es deficitario respecto de las comunes u ordinarias” (MONTOYA, GALIANA, SEMPERE y RIOS, 2000:32; OJEDA, 1990:227; CAVAS, 1994:78; MORENO, 1998:72) ${ }^{3}$, pues aunque esa separación de regímenes jurídicos no vulnere el principio de igualdad, ni se traduzca en discriminación para los colectivos afectados implica la privación de alguna de las garantías reconocidas por la legislación laboral común, lo que comporta un perjuicio para estas personas trabajadoras con un régimen jurídico más desfavorable y menos protector .

Debemos precisar que, dentro de esta pluralidad de criterios doctrinales, existe coincidencia entre los autores en que las relaciones laborales especiales tienen un régimen jurídico diferente del común, pues ése es el resultado de la distinción de especial. De entre estos criterios, podemos destacar, los que califican las relaciones laborales especiales como cauce para el establecimiento de regímenes jurídicos menos favorables que el común, que

no vulneran el principio de igualdad ni se traducen en discriminación para los colectivos afectados, aunque para éstos implique la privación de alguna de las garantías reconocidas por la legislación laboral común (CAVAS, 1994;78-79).

También ha sido admitida por la doctrina, que esa desprotección no se fundamenta exclusivamente en las peculiaridades de la relación, sino que es

una fórmula sofisticada de liberalizar con garantías, una manera quizá vergonzante de mantener apartados de la plena laboralidad a colectivos que no obstante se considera merecedores de algún nivel de protección (OJEDA,1990:239).

\footnotetext{
${ }^{3}$ MONTOYA, GALIANA, SEMPERE y RIOS, consideran que el legislador, más que inspirarse en una razón o fundamento teórico, ha conceptuado las relaciones laborales especiales con la finalidad práctica de dotarlas de regulaciones distintas a la contenida en el ET y demás normas laborales comunes; OJEDA, las define como "aquellas dotadas de normas específicas y distintas a las de la relación laboral común”; CAVAS, reitera que, a partir de ser calificadas como especiales quedan sujetas a normas específicas, con exclusión, en principio, de la legislación laboral común; MORENO, afirma que "la calificación jurídica de relaciones especiales viene dada fundamentalmente por el establecimiento de un régimen jurídico diverso en las relaciones consideradas especiales frente al régimen jurídico aplicable al contrato común”.
} 
La jurisprudencia también ha subrayado indirectamente esa limitación a la protección de la persona trabajadora sometida a un régimen jurídico especial. Así, la Sentencia del Tribunal Supremo de 4 de junio de 1999 considera que:

...la aplicación de un régimen jurídico especial en el que se limita de forma importante la protección que el ordenamiento otorga a los trabajadores, no puede ser objeto de una interpretación extensiva.

La sentencia predica que se debe interpretar de forma restrictiva el régimen de protección especial, ya que la incidencia o especificidad, así como la presencia de otros factores relacionados con la tarea a desempeñar o lugar donde se realiza, no pueden utilizarse como justificación para limitar la protección de estos trabajadores.

Podemos entender, por tanto, que en aquellas relaciones de trabajo en las que, dándose las notas de la laboralidad, por sus especiales características, llevaron al legislador a otorgar a estas relaciones laborales, un régimen jurídico distinto del propio de las relaciones comunes, en general, son menos favorables en comparación con éste (GARCÍA, 2019:534-557).

Las condiciones de menor protección se dan, por ejemplo, en unos casos, en la extinción del contrato (BENAVENTE, 2019: 534-557), como ocurre con la relación laboral especial del Personal de Alta Dirección o la relación laboral especial del Servicio del Hogar Familiar ${ }^{4}$, relaciones en las que el empresario o titular del hogar familiar pueden desistir de la relación laboral sin alegar causa alguna.

En otros supuestos es la duración del contrato, necesariamente temporal, como ocurre en la relación laboral especial de Deportistas Profesionales y en la relación laboral especial de Artistas en Espectáculos Públicos, y en otros casos, el perjuicio va a venir de la imposibilidad de ejercicio de derechos colectivos, como en el caso de la relación laboral especial de los Penados en Talleres Penitenciarios, que no pueden ejercer todos o alguno de los derechos colectivos tal como vienen configurados en el ordenamiento laboral común. Incluso en relaciones laborales especiales en las que existe una mayor protección que la otorgada por el ordenamiento laboral común (OJEDA, 1990:239), como el supuesto de la relación laboral especial de Minusválidos en Centros Especiales de Empleo (OJEDA, 1988:152), dirigida a un trabajador "protegido" por una regulación "intervencionista-paternalista”, que puede tildarse de indiscriminada (ESTEBAN, 1990: $284)^{5}$.

Por esta razón, debemos analizar, dentro de la lista abierta que nos ofrece el artículo 2 del ET 6 , y en las fuentes reguladoras de las relaciones laborales especiales, los “criterios de especialidad" y protecciones asociadas a este colectivo y es que la naturaleza de la actividad, el lugar de trabajo, las condiciones de ejecutar la prestación o la organización productiva son criterios válidos, es decir, no existe un concepto unitario de especialidad,

4 En el caso de una concreta relación laboral especial, la de servicio del hogar familiar, indica el Tribunal Constitucional que el ET produjo una deslegalización del régimen jurídico aplicable con anterioridad, contenido en el artículo 1584 del Código Civil, por lo que no sería de aplicación. STC 26/1984, de 24 de febrero, (BOE de 9 de marzo), F.J. $5^{\circ}$.

5 Resalta que, en algunos aspectos, la línea de protección se basa más en la "debilidad sindical” que en sus propias limitaciones.

6 Artículo 2 del ET: Cláusula abierta según la cual se consideran también relaciones laborales especiales cualquier otro trabajo que sea expresamente declarado de este modo por una ley. 
son distintas particularidades las que convierten ciertas relaciones laborales en especiales (MONTOYA, 2000: 10) ${ }^{7}$.

En el supuesto analizado, las especialidades de la regulación de esta relación laboral se han fundamentado en las características estructurales del tipo de trabajo que se lleva a cabo y en el ámbito en que se produce. Su especialidad reside realmente en que se presta para un ámbito "empresarial” especial, esto es en el hogar familiar y para su titular, entendiendo por tal una persona física o grupo de personas, en cuyo ámbito se prestan los servicios, y es cierto que mediante este trabajo se produce la inserción del trabajador en “el círculo de convivencia e intimidad de la familia”.

En efecto, la propia Exposición de Motivos del RLESD, reconocía que es precisamente el ámbito de la prestación de servicios, es decir, el hogar familiar, y la necesidad de que se base en la mutua confianza de las partes, los factores determinantes de las especialidades que con respecto a la legislación laboral común se prevén en esta norma, ya que ello determina, como hemos adelantado en párrafos anteriores, la necesidad de que esta relación se base en la mutua confianza de las partes, por lo que no podemos olvidar que en el ámbito familiar en el que se desarrolla el trabajo se proyectan, como hemos adelantado, derechos constitucionales, relativos a la intimidad personal y familiar.

En este sentido, el Tribunal Supremo, en su sentencia de 20 de febrero de 1989 establecía que

la esfera privada... incluye aquel sector de circunstancias que, sin ser secretas ni de carácter íntimo, merecen, sin embargo, el respeto de todos, por ser necesarias para garantizar el normal desenvolvimiento y la tranquilidad de los titulares particulares...,

De ello se deduce el distinto tratamiento que da el Alto Tribunal a la vida privada y a la intimidad ${ }^{8}$.

\subsection{Evolución normativa de la Relación laboral especial del servicio del hogar familiar desde su inclusión estatutaria}

En un primer análisis, se puede identificar esta relación laboral especial como "la que conciertan el titular del mismo como empleador, y la persona que, dependientemente y por cuenta de aquél, presta servicios retribuidos en el ámbito del hogar familiar”9. En este sentido, sus derechos laborales y de seguridad social se desarrollaron con más de cincuenta años de retraso con respecto al de las personas trabajadoras en su conjunto (PANIZO, 2013:5-58), debido a las actividades que implica y a las relaciones que se establecen en su seno.

En esta relación destaca la íntima, forzosa y continuada convivencia en el limitado espacio del hogar familiar de tal forma que la prestación del servicio tiene un componente especial y subjetivo de mayor importancia que el del resultado del trabajo o la cuantía de la retribución. La confianza se convierte en elemento fundamental de la relación de

7 Afirma que "no ha prosperado la idea de definir la relación especial de trabajo en atención a un criterio único”.

${ }^{8}$ Incluso el legislador ha sido consciente de esta diferencia en varias normas, destacando la Ley Orgánica 1/1982 de protección civil del derecho al honor, que habla de vida privada como algo distinto a los escritos íntimos en su artículo 7.3. También lo hace la Exposición de Motivos de la antigua Ley Orgánica 5/1992, de 29 de octubre, de Regulación del Tratamiento Automatizado de los Datos de Carácter Personal.

9 Por lo que llegamos a la conclusión, que para ser considerado trabajador por cuenta ajena y estar sometido al ámbito de aplicación del ET, es necesario prestar dicho trabajo bajo las características de voluntariedad, dependencia, ajeneidad y que la relación sea retribuida. STS 19 enero 1987. 
trabajo y en una exigencia del funcionamiento de ésta, pero como se ha puesto de relieve doctrinalmente, la confianza es un elemento esencial para el empleador, pero carece de tal relevancia vital para la persona trabajadora (GARCÍA, 1987:1625-1626).

Ante esta situación, y como ya hemos advertido, el RLESD supuso sin duda un avance al considerar el trabajo doméstico como una relación laboral, pero no obstante, diversos autores lo han caracterizado como un ingreso a "medias" de esta actividad en el área titulada laboral, ya que en última instancia la acaba definiendo como una relación laboral especial que conserva buena parte de los rasgos civilistas "privados" originarios que ha supuesto la ausencia de una verdadera regulación laboral equiparable a la del resto de trabajadores (LÓPEZ Y TOSCANI, 2006:7).

Tras las premisas de flexibilidad, buena fe y relación de confianza establecidas en su declaración de intenciones, el RLESD legaliza cuestiones como la ausencia de contrato escrito o de derecho al subsidio del paro, la presunción de temporalidad, el despido libre barato y la incapacidad de los inspectores de trabajo de acceder a este ámbito de trabajo. Además, de manera similar a las interminables jornadas laborales de las trabajadoras domésticas de inicios del siglo XX descritas por Martínez Veiga, el RLESD permitía la existencia de jornadas de más de doce horas sin explicitar su remuneración total (MARTINEZ, 1995:135).

En general, el RLESD da lugar a una regulación desequilibrada que, sobre la base de las características especiales de la relación (relación personal, de confianza, trabajo llevado a cabo en el círculo de convivencia e intimidad de la familia) y tras el eufemismo de la "autonomía de las partes”, acaba dando prevalencia a la posición especial de la parte empleadora frente a los derechos de la persona trabajadora. De esta manera, el RLESD supone en realidad la entrada del trabajo doméstico al ámbito laboral por la "puerta falsa" y “configura a los empleados del hogar como trabajadores, pero sólo a medias” (LÓPEZ Y TOSCANI, 2006:9).

De hecho, en ese momento este colectivo se encontraba en un Régimen Especial de la Seguridad Social en el que solo se protegían las contingencias comunes, con independencia de que la enfermedad o el accidente de la persona empleada de hogar tuvieran, respectivamente, carácter laboral, o no lo tuvieran. No obstante, la Ley 39/2010, de Presupuestos Generales del Estado para el año 2011, vino a corregir tal situación y, extendió la acción protectora por contingencias profesionales prevista en el Régimen General a los trabajadores incluidos en este Régimen Especial, en los términos y condiciones que se establecieran reglamentariamente ${ }^{10}$. El RD 1596/2011, de 4 de noviembre, procedió al oportuno desarrollo reglamentario en materia de prestaciones, con el objeto de hacer plenamente efectiva la nueva extensión de la acción protectora.

También en relación con el salario en especie en este colectivo ha presentado en el pasado reciente particularidades con respecto al régimen ordinario. La norma contenida en el art. 6.2 del RLESD, establecía que en los casos en los que se dieran prestaciones de servicios con derecho a prestaciones en especie como alojamiento y manutención, se

\footnotetext{
${ }^{10}$ La primera modificación se había llevado a cabo por la Ley 39/2010, de 22 de diciembre, de presupuestos Generales del Estado para 2011, que añade la disposición quincuagésima tercera a la Ley General de Seguridad Social, por la que se extiende desde el 1 de enero de 2011 la acción protectora por contingencias profesionales a los trabajadores incluidos en el Régimen Especial de Empleados de Hogar que hasta entonces estaban privados de ella. El desarrollo de la disposición adicional quincuagésima tercera de la Ley General de 1994 tendría lugar por el RD 1596/2011, de 4 de noviembre, en relación con la extensión de la acción protectora por contingencias profesionales.
} 
podría descontar por tales conceptos el porcentaje que las partes acordasen sin que dicho descuento pudiera superar el porcentaje superior al $45 \%$ del salario total. Ello suponía un incremento con respecto al tope total para las remuneraciones en especie que recogía el art. 26 ET, que era un límite del 30\%.

En este sentido y por las dificultades para cuantificar dichas percepciones y las prácticas abusivas que dejaban el salario en metálico reducido a cantidades mínimas, aconsejaban una reforma que introdujo la Ley 35/2010 al imponer un límite más rígido a la percepción de prestaciones salariales en especie pues, en ningún caso, incluidas las relaciones laborales especiales, el salario en especie podrá superar el 30\% de las percepciones salariales del trabajador, ni dar lugar a la minoración de la cuantía íntegra en dinero del salario mínimo interprofesional ${ }^{11}$.

Antes de que se aprobase el desarrollo reglamentario sobre la materia, se promulgó la Ley 27/2011, de 1 de agosto, sobre actualización, adecuación y modernización del sistema de Seguridad Social, cuya disposición adicional 39a ordena la integración del Régimen Especial de Empleados de Hogar en el Régimen General de la Seguridad Social mediante un Sistema Especial ${ }^{12}$. Y ha sido con posterioridad a esta última norma cuando se ha dictado el Real Decreto 1596/2011, de 4 de noviembre, por el que se desarrolla la extensión de la acción protectora por contingencias profesionales a los trabajadores incluidos en el Régimen Especial de Empleados de Hogar, cuya entrada en vigor se producirá el 1 de enero de 2012, es decir, cuando este régimen especial ya esté subsistiendo transitoriamente.

En este sentido, reseñar que la integración de los empleados de hogar en el Régimen General de la Seguridad Social se produce mediante la creación de un sistema especial dentro de éste con efectos a 1 de enero de 2012. No obstante, el Régimen Especial de Empleados de Hogar pervivirá transitoriamente hasta el 1 de julio de 2012, pues durante ese tiempo se seguirán aplicando sus normas hasta que se produzca el trasvase de los trabajadores de uno a otro régimen en los términos y condiciones como hemos adelantado.

La creación del Sistema especial adolece, de ciertos déficits, y en particular, en el momento actual, debe criticarse la técnica legislativa, muy poco ortodoxa, porque la creación del Sistema especial y su regulación esencial se contienen en una Disposición Adicional de una ley concebida para reformar las pensiones y contribuir a la viabilidad del Sistema, y no se ha aprobado un desarrollo reglamentario, ni una norma diseñada específicamente para este Sistema especial.

Es a partir de 2011 por tanto cuando nos encontramos con los primeros cambios, y como se había anunciado en la DA $39^{a}$ de la Ley $27 / 2011^{13}$, se señala que es el relativo a la esfera de las relaciones laborales con la entrada en vigor del Real Decreto 1620/2011

\footnotetext{
${ }^{11}$ Esta es una medida que se ha reflejado expresamente en el art. 8.2 del RD 1620/2011.

${ }^{12}$ El art. 10.1 del Real Decreto Legislativo 8/2015, de 30 de octubre, por el que se aprueba el texto refundido de la Ley General de la Seguridad Social contiene la previsión del establecimiento de regímenes especiales en aquellas actividades profesionales que, por su naturaleza, sus peculiares condiciones de tiempo y lugar de trabajo o por la índole de sus procesos productivos, se hiciese preciso para una más adecuada aplicación del sistema de protección de la Seguridad Social. Entre estos regímenes se encontraba el de empleados de hogar que, tras la modificación introducida por la Disposición Adicional cuadragésima, de la Ley 27/2011Ley 27/2011, de 1 de agosto, sobre actualización, adecuación y modernización del sistema de Seguridad Social ha quedado integrado en el Régimen General con efectos 1 de enero de 2012.

${ }^{13}$ Esta Ley extinguió el Régimen Especial de Empleadas de Hogar para crear un Sistema Especial del Régimen General. El sistema especial de empleados de hogar está regulado en la Sección $1^{\text {a }}$ del Capítulo XVIII del Título II de la LGSS, aprobada por RD legislativo 8/2015, de 30 de octubre.
} 
de 14 de noviembre, por el que se regula la relación laboral de carácter especial del servicio del hogar familiar (en adelante RLESHF), inspirado en el Convenio de la Organización Internacional del Trabajo (en adelante OIT) adoptado por la Conferencia el 16 de junio de 2011 (Convenio 189 y Recomendación 20144) "Trabajo decente para las trabajadoras y trabajadores domésticos” ${ }^{15}$ que instaura una nueva regulación de esta relación laboral especial ${ }^{16}$, conservando el carácter especial de esta relación laboral, si bien procede a una revisión del RLESD, ya que como hemos anticipado, la doctrina venía demandando su adecuación normativa mediante la mejora en la protección de los derechos reconocidos a este colectivo (GRAU, 2019:47-90).

La adaptación de la normativa se planificó con un calendario que abarcaba de 2012 a 2018, en función de la complejidad de las materias a adaptar. En diciembre de 2012, sin embargo, se produjo una modificación parcial de las reglas de Seguridad Social aplicables a las personas que "prestan servicios en el hogar familiar", fundamentalmente en relación a la afiliación de las trabajadoras por horas y a los tramos de cotización, que entró en vigor en abril de 2013 a través del Real Decreto Ley 29/2012 ${ }^{17}$.

Retomando el RLESHF, su objetivo principal consistía en la equiparación gradual de las prestaciones del trabajo del colectivo doméstico con el resto de personas trabajadoras (LÓPEZ Y TOSCANI, 2012:67-72), siguiendo como decimos, las recomendaciones de la OIT, ya que nos encontramos con artículos del mencionado Convenio donde se garantizan algunos derechos en conexión, en gran medida, con la Declaración de la OIT relativa a los principios y derechos fundamentales en el trabajo, como son la libertad de asociación y la libertad sindical de trabajadores y empleadores domésticos y el reconocimiento efectivo de su derecho de negociación colectiva (art. 3.2.a), obligando en particular a los Miembros a la protección del derecho de los trabajadores domésticos y de los empleadores de trabajadores domésticos a constituir las organizaciones, federaciones y confederaciones que estimen convenientes y, con la condición de observar los estatutos de estas organizaciones, a afiliarse a las mismas (art. 3.3). Este terreno sindical, hay que ampliarlo con la limitación del trabajador doméstico extranjero a la constitución de sindicatos, aunque por supuesto no existen impedimentos a la afiliación a los ya constituidos (SANZ, 2021:228).

Sin embargo, esta nueva norma, aunque incluye mejoras, parece quedar solo en propuestas sin resolver, como podemos observar en la DA $2^{\mathrm{a}}$ del RLESHF en la que se establece una revisión en materia de extinción del contrato y sobre la aplicación del sistema de protección por desempleo. A pesar de ello, es este uno de tantos proyectos que se encuentra durmiendo el sueño de los justos. (LLORENS, 2020:174).

\footnotetext{
${ }^{14}$ El Convenio núm. 189 entró en vigor el 5 de septiembre de 2013, doce meses después de la fecha de ratificación de dos Estados miembros.

${ }^{15}$ Anteriormente, se hicieron ya varios intentos en la OIT para mejorar las condiciones de los trabajadores y trabajadoras del hogar. El primero fue en 1948, cuando se adoptó una resolución relativa a sus condiciones de empleo. En 1965, se adoptaría una nueva resolución pidiendo una acción normativa en la materia, aunque nunca llegó a implementarse. En 1970 se publicó el primer estudio sobre el estatus de los trabajadores/as del hogar en todo el mundo. Pero no sería sino hasta 2010 cuando se iniciaran las negociaciones para la aprobación de una norma internacional sobre trabajo decente para los trabajadores y trabajadoras del hogar. ${ }^{16}$ El 16 de junio de 2011, la Conferencia Internacional del Trabajo dio un paso histórico en la lucha por la justicia social en todo el mundo al adoptar el Convenio 189 OIT y la Recomendación 201 OIT sobre trabajo decente para las trabajadoras y los trabajadores domésticos.

${ }^{17}$ Real Decreto Ley 29/2012, de 28 de diciembre, de mejor gestión y protección social en el sistema especial para empleados de hogar y otras medidas de carácter económico y social.
} 


\section{Reconocimiento de los derechos colectivos para el trabajo doméstico remunerado}

Cuando hablamos de derechos colectivos en una estructura relacionada con la prestación del trabajo personal, lo habitual es reconocer el término dentro del ámbito colectivo del Derecho del trabajo, y dentro de éste, con las herramientas propias de tutela colectiva reconocidos constitucionalmente a quien presta su trabajo retribuido por cuenta de otro: el derecho de libertad sindical, reconocido en el art. 28.1 de nuestra Constitución española de 1978 (en adelante CE) que, junto con la negociación colectiva y la huelga, constituyen

los tres elementos medulares del fenómeno colectivo protagonizado por la clase trabajadora desde el comienzo de su actuación social como tal en defensa de sus propios intereses (ALARCÓN, 1995;57).

Considerándose efectivamente como mecanismos colectivos que, si bien aparecieron en un contexto histórico, social, político y económico determinado, ante la necesidad de proporcionar amparo a la parte objetivamente más frágil de la relación laboral, como es la persona trabajadora. Siguen siendo hoy día, por esencia, instrumentos de tutela colectiva de la clase trabajadora, reconocidos, como hemos anticipado ya, por el artículo 2.2 del ET, así como por el silencio del RLESHF que supone la aplicación supletoria de la normativa laboral común, compatible con las peculiaridades de la relación laboral especial.

Ante esta situación el RLESHF continúa, como la legislación anterior, sin hacer ninguna referencia a los derechos colectivos de estas trabajadoras, ni los prohíbe, ni los reconoce, ni los regula, lo que supone, en ciertos casos un alto grado de dificultad que roza la imposibilidad de su ejercicio por las peculiaridades que se dan en esta relación especial que radican en la singularidad del lugar de trabajo (hogar familiar) y en otras dos características sustanciales: la necesaria e imprescindible convivencia y cercanía entre la parte trabajadora y la empleadora, unidas a una dirección y medidas de control muy estrechas por parte de esta última, que siempre ha de ser persona física.

Por esta razón, hubiese sido acertado facilitar, no sólo permitir, el ejercicio de los derechos fundamentales del trabajador dentro del hogar familiar (PEDRAJAS, 1992:6465), sin alterar su funcionamiento en el ámbito que se trata de ejercitar, con la interpretación más favorable a dichos derechos (FERNÁNDEZ, 1985:65), buscando como realizar ese ajuste entre los derechos del trabajador doméstico y los del titular del hogar familiar siendo extensivo a quienes conviven en el mismo.

Por ese motivo, debería ser tarea de las normas que regulan los derechos del trabajador, algunas de ellas orgánicas por el carácter de fundamentales de los mismos (QUESADA, 1991:101), siendo más necesaria en la relación laboral especial de trabajadores al servicio del hogar familiar porque en ella se dan una serie de circunstancias del lado de la parte trabajadora que no existen entre otras con relación especial. Tengamos en cuenta un dato importante como es el aislamiento en que se produce el trabajo al servicio del hogar familiar. En muchos casos existe una única 
trabajadora doméstica en el hogar familiar, y, en muchas ocasiones también, su actividad se realiza sola, sin compañía de quienes conviven en el hogar familiar ${ }^{18}$.

A las mencionadas dificultades debemos unir, la posible colisión de derechos que se pueden dar entre la parte empleadora y la empleada por la confianza que tiene que darse en la relación laboral. Pero ante esto, entendemos que, si para solucionar este último supuesto el RLESHF ofrece a la persona empleador la posibilidad de desistir de la relación especial, como ya venía permitiendo la regulación anterior, el ordenamiento jurídico debería potenciar el ejercicio de la autonomía colectiva de estos trabajadores para equilibrar la situación de desigualdad (FERNÁNDEZ, 1985:64).

A pesar de ello, es evidente que la persona trabajadora doméstica puede acudir a la Jurisdicción Social para resolver los conflictos derivados del incumplimiento de la normativa laboral (QUESADA, 1991:100). Pero en el caso de esta relación laboral especial basada en la mutua confianza entre las partes, con las diferencias apuntadas anteriormente entre empleador y trabajador, que tiene en el desistimiento del empleador una de sus manifestaciones más características ${ }^{19}$, es fácil pensar en la utilización de este que hará el empleador, al haber “defraudado" esa confianza la reclamación del trabajador (GARCÍA, 1987:1630) ${ }^{20}$.

\subsection{Algunas consideraciones sobre la libertad sindical del servicio doméstico}

La realidad constata que es un colectivo con un bajo nivel de afiliación (SALA, 1986:315), debido, entre otros factores, a la feminización y aislamiento en que se realiza la actividad (GARCÍA, 1987:1628) ${ }^{21}$. Nada impide, sin embargo, la afiliación a sindicatos ya constituidos o la constitución de sindicatos específicos para personas trabajadoras domésticas. No obstante, en el terreno sindical, hay que sumar la limitación de la trabajadora doméstica extranjera a la constitución de sindicatos, aunque por supuesto no existen impedimentos de afiliación a los ya constituidos ${ }^{22}$.

De lo anterior deducimos, que no deben existir obstáculos para que la trabajadora afiliada pueda ejercer sus derechos sindicales en el interior del hogar familiar, ya que no supone atentar a la intimidad familiar, que estas trabajadoras constituyan secciones sindicales en su lugar de trabajo, ni que se reúnan las afiliadas a un sindicato, así como a que reciban información del mismo. La realidad, sin embargo, imposibilita el ejercicio de

\footnotetext{
${ }^{18}$ Puntualizar que en la actualidad existen organizaciones sindicales de rama que representan los intereses del colectivo como el Sindicato Independiente de Trabajadoras del Hogar y los Cuidados SINDIHOGAR/SINDILLAR, creado en Barcelona en 2011; o más recientemente, en enero de 2021, el Sindicato de Trabajadoras de Hogar y Cuidados, SINTRAHOCU, organización sindical de ámbito estatal, ${ }^{19}$ En este supuesto, la parte empleadora abonará a la trabajadora una indemnización de doce días por cada año trabajado con el límite de nueve mensualidades. Además, se deberá de realizar un preaviso de 20 días en caso de que la relación laboral supere el año de duración, o de siete días en caso contrario. Si el preaviso no se cumple, se deberá de abonar un día de salario por cada día de ausencia de preaviso. La indemnización debe abonarse en el momento que se comunica la extinción de la relación laboral en metálico.

${ }^{20}$ Así lo manifiesta García López, en el caso del despido al afirmar que "el deterioro inicial de la confianza generadora del acto de despido se verá agravada con la impugnación del trabajador, el planteamiento del proceso y el resultado del mismo.

${ }^{21}$ Utilizaremos el femenino para aludir a los trabajadores y trabajadoras del trabajo doméstico, por ser la presencia de estas últimas más relevante desde un punto de vista cualitativo y cuantitativo.

${ }^{22}$ Siempre que se cuenten con autorización de estancia o residencia en España, requisito previsto en el artículo 11 de la Ley Orgánica 4/2000, de 11 de enero, sobre derechos y libertades de los extranjeros en España (BOE de 12 de enero), modificada por la Ley 8/2000, de 22 de diciembre (BOE de 23 de diciembre).
} 
tales derechos, por el número de trabajadoras domésticas en un hogar familiar, en la mayoría de los casos una, con un número tan reducido se frena su ejercicio, sobre todo, aquellos que tienen su razón de ser en que sea colectivo.

Sí podría entenderse como atentado a la intimidad del hogar, la asistencia y acceso de los cargos electivos de los sindicatos más representativos para realizar actividades del sindicato o de los trabajadores, según establece el artículo 9.1.c) de la Ley Orgánica de Libertad Sindical, pero en todo caso, consideramos que deberán establecerse las mismas prevenciones que el RLESHF fija para la actuación de control del cumplimiento del ordenamiento laboral y de Seguridad Social por parte de la Inspección de Trabajo y Seguridad Social, en la medida en que el representante se convierte en "una especie de inspector sindical” (ALBIOL, 1990:122).

No obstante, como para la existencia de representantes en el lugar de trabajo se exige, un número mínimo de diez personas trabajadoras, cosa por otro lado poco probable en la mayoría de hogares familiares (NAVARRO, 1993:24), y aun no existiendo una excepción a esta regla general en la que permite que en los centros de trabajo que cuenten entre seis y diez personas trabajadoras, puedan éstas decidir por mayoría elegir un delegado/a de personal que les represente, incluso con esta reducción legal, no facilita la escasa posibilidad de elección de representante, pues sigue siendo excesivo el número de trabajadoras necesario para contar con representación en el ámbito del hogar familiar, incluso con dicha reducción.

Para conseguir sus objetivos se utiliza "una configuración que paute las formas de reivindicación, en este caso, se seleccionan las formas de acción política convencional” (VALLES, 2007:291), en concreto, las asociaciones ${ }^{23}$, agrupaciones formalizadas a través del alta en el Registro de Asociaciones (Ministerio del Interior), y voluntarias, que "trabajan de forma cooperativa en busca de un objetivo común” (ARIÑO, 2004:85-110). Pero para lograr la equiparación de derechos con el resto de las personas trabajadoras, sería necesario, plantearse la necesidad de un desarrollo del trabajo político para evitar los obstáculos con los que se encuentran para la sindicalización (BLASCO, 2019:411419).

Otro inconveniente en este colectivo relacionado con la libertad sindical es el de la inexistencia de organizaciones patronales de personas empleadoras del hogar familiar, ya que en cuanto sujetos del sistema de relaciones laborales, tienen reconocidos medios colectivos de organización y de negociación, no siendo titulares de la libertad sindical: el derecho a constituir organizaciones empresariales, así como asociarse a las mismas “específicamente reconocidos a nivel de legalidad ordinaria” (MONEREO, 2002: 625697).

Estas organizaciones tienen también el mismo reconocimiento constitucional que los sindicatos, desde la óptica de la función que deben desarrollar de defensa de los intereses económicos y sociales que le son propios (art. $7 \mathrm{CE}$ ). Igualmente, los

\footnotetext{
${ }^{23}$ Las organizaciones y asociaciones de trabajadores/as del hogar han consagrado años de dedicación y lucha para conseguir el reconocimiento legal y el respeto por su trabajo. Han estado haciendo campaña durante años para erradicar la explotación y los abusos. Por tanto, aunque sin legitimación para negociar convenios colectivos indicar que existen asociaciones como ATH-ELE (Asociación de Trabajadoras del Hogar de Bizkaia) o como SEDOAC (Servicio Doméstico Activo).
} 
empresarios y sus organizaciones tienen reconocidos los derechos de negociación colectiva laboral y de adopción de medidas de conflicto colectivo (art. 37 CE 55).

Desde una perspectiva formal, en principio, no habría inconveniente legal a que se creasen asociaciones patronales específicas para la defensa de sus intereses, incluso podrían ser sustituidas por otro tipo de asociación que no fuese en puridad una asociación empresarial vinculada a los arts. 7 y 22 CE, caracterizada en exclusividad por el campo en que aquéllas actúan, y en los medios de acción que el ordenamiento coloca a su disposición, cuales son la negociación colectiva laboral, el planteamiento de conflictos colectivos de trabajo, el diálogo social y la participación institucional en los organismos públicos de las Administraciones laborales. Tampoco sería insalvable el aparente conflicto en el supuesto de que en una misma persona concurra la cualidad de afiliado a un sindicato y a una patronal en calidad, respectivamente, de trabajador y empleador en el ámbito del hogar familiar. Nuevamente, los inconvenientes son otros: su inexistencia y su carácter insustituible.

\subsection{Consideraciones generales sobre la negociación colectiva en esta relación laboral especial}

Como el resto de los derechos colectivos también el contenido en el artículo 37.1 de la C.E., a la negociación colectiva, es aplicable a esta relación laboral. Pero al no adecuarse la normativa de éste derecho a las peculiaridades de esta relación laboral especial, ya que apenas se hace referencia al convenio colectivo ni a su "eficacia vinculante", ni mucho menos se regula el propio derecho a la negociación colectiva en el colectivo, ni tampoco derechos de representación, dificultan la práctica de éste derecho, cuando sería importante para equilibrar a las partes de la relación, pasando a la mejora colectiva de intereses y dejando de lado el carácter esencialmente contractual de la relación (QUESADA, 1991:103).

De este modo, y examinando el sistema de fuentes del art. 3 del RLESHF, se podría presumir de forma apresurada el alcance del convenio colectivo en la regulación de las obligaciones y derechos de esta relación laboral especial (CORDERO, 2014:54-63). Así, el art. 3.c) reconoce formalmente entre sus fuentes reguladoras al convenio colectivo, además, el apartado b) del mismo artículo, admite entre las fuentes de la relación laboral, con carácter supletorio en aquello que sea compatible, la normativa laboral común y el 3.d) declara al contrato de trabajo como fuente de las condiciones de trabajo, siempre con respeto a las leyes y al convenio colectivo, por lo que no parece que se evidencien diferencias esenciales entre este artículo y el 3.1 del ET.

Por otra parte, también el art. 7 del RLESHF reconoce a las trabajadoras del servicio del hogar familiar los derechos y deberes laborales establecidos en el mismo y en los arts. 4 y 5 del ET. Es más, el art. 2.2 del ET, ya dispone que la regulación de las relaciones laborales respetará los derechos básicos reconocidos por la Constitución. Concretamente, la remisión del art. 7 del RLESHF al art. 4.1 del ET, supone el expreso reconocimiento de los derechos básicos de las personas trabajadoras, con el contenido y alcance que para cada uno de los mismos disponga su específica normativa: entre otros, los derechos de libre sindicación, negociación colectiva, adopción de medidas de conflicto colectivo, huelga, reunión, e información, consulta y participación.

Destaca sin embargo que, a diferencia del ET, plagado de remisiones a la negociación colectiva, en el RLESHF, las referencias al convenio colectivo son realmente 
escasas y se limitan específicamente al período de prueba (art. 6.2) y a la retribución (art. 8.1 y 3). Y aunque pueda significar que subsista con ello una limitación para la negociación colectiva de esta relación laboral especial, es cierto que queda patente una diferenciación formal respecto del tratamiento de la negociación colectiva en el precedente RLESD, ya que éste no reconocía expresamente el convenio colectivo como fuente, así como tampoco la aplicación del art. 4 del ET, deduciéndose tan sólo su posibilidad de la referencia del art. 6. Uno sobre retribuciones, a la posible mejora del salario mínimo interprofesional a través de pacto individual o colectivo, y a la Disposición Adicional que declaraba como supletoria la regulación laboral común en lo que fuese compatible con las peculiaridades derivadas del carácter especial de la relación.

Es evidente que el convenio colectivo es fuente reguladora de esta relación especial, por tanto, cuando el RLESHF, se remite explícita o implícitamente al pacto entre las partes sin expresa referencia al convenio colectivo, podemos entender que está permitiendo que esté por encima del mismo, por lo que será necesario concretar respecto a qué condiciones de trabajo se refiere y siempre que se encuentre bajo el filtro de la compatibilidad del ET con su normativa específica.

Recordemos, como ha declarado el Tribunal Supremo precisamente en un contexto tradicionalmente muy reductivo de las capacidades reguladoras de la negociación colectiva cual es el de las modalidades contractuales, que la negociación colectiva no necesita en estricto de una autorización para intervenir en un determinado ámbito material, pues nuestro sistema de negociación colectiva no está basado en la previa apertura legal de las materias que pueden abordarse. Por el contrario, los artículos $37 \mathrm{CE}$ y 85 ET, en concordancia con numerosos textos internacionales, abocan a una libertad de contenidos solo limitada por las prohibiciones y presidida por la jerarquía normativa. Por consiguiente,

sin contrariar la literalidad o la finalidad de la regulación heterónoma, la negociación colectiva puede desarrollar o clarificar el alcance, adoptar cautelas para que se cumplan los mandatos normativos... incluso en el marco de las modalidades contractuales en ausencia de remisión específica.

Ante esta situación, podrían mejorarse los mínimos reconocidos por el RLESHF mediante la negociación entre las partes, reforzándose por la negociación colectiva propia del sector, pero para eso el RLESHF debe prever las posibles dificultades que se den a la hora de negociar convenios colectivos. Para ello, este colectivo, debe tener una regulación suficiente o posibilitar la extensión a convenios afines, pero como ya hemos expuesto en el epígrafe anterior, nos encontramos con un problema aún más grave, la falta de la parte empresarial para negociar, dada la inexistencia de asociaciones de titulares del hogar familiar.

En cuanto a esta inexistencia, tras la reforma de los arts. 87.3.c) y 88.2 ET por el RDL. 7/2011, de 10 de junio, de medidas urgentes para la reforma de la negociación colectiva, y pese a la breve duración de esta norma, por la casi inmediata reforma por obra del Real Decreto-Ley 3/2012, de 10 de febrero, de medidas urgentes para la reforma del mercado laboral (posteriormente convalidado como Ley 3/2012, con algunos cambios), las reglas de legitimación para negociar convenios colectivos estatutarios quedaron inalteradas, si bien en un contexto normativo diferente al haber cambiado el resto de las "piezas" del sistema legal de negociación colectiva (OLARTE, 2013: 483508), desafiando por tanto a la superación de la imposibilidad de su negociación por 
inexistencia de asociaciones patronales suficientemente representativas en la unidad de negociación.

Ante esta situación, el problema a resolver no sería tanto la falta de representatividad, reparable con la referida modificación normativa, sino más bien, de un problema de falta de constitución y existencia real del sujeto colectivo en dicho ámbito específico y tan particular de actividad. En tal caso, más que hablar de representatividad, estaríamos ante la imposibilidad de representación, de negociar más allá del ámbito de la asociación y de afección de los derechos de terceros ajenos a la misma (BENAVENTE, 2021:534-557).

Ligada a la negociación, pero como una característica diferente está la falta de definición de las funciones laborales. La configuración de esta relación laboral especial es imprecisa al no definir las tareas y no diferenciar entre limpieza y cuidados (CARRANSCO, BORDERÍA Y TORNS, 2011:143), quedando a disposición del titular del hogar familiar. Esto puede predisponer al aumento del trabajo, imposibilitando la cuantificación de sus límites. La intensificación del trabajo debe consistir en el "incremento de las funciones y tareas por trabajador/a en el marco de una jornada laboral y una remuneración económica prefijadas al incremento” (CASTILLO, 1998:43).

Todo ello, porque el tiempo de trabajo es un elemento que estructura las condiciones laborales de las personas, establece su dedicación y la organización y distribución de sus tiempos de trabajo, por lo que tienen importantes consecuencias en la salud, la conciliación de la vida personal y laboral y condiciones de vida de estas trabajadoras, por lo que siempre ha sido uno de los objetivos de la negociación colectiva.

Convenimos sin duda, en la dificultad de aplicar a este colectivo, sin ninguna adaptación normativa, la regulación establecida con carácter general sobre libertad sindical, así como la dificultad en la práctica, de la negociación colectiva en una relación laboral con una tendencia marcadamente individualizada, lo que nos permite comprender algunas de las causas de que no haya ningún convenio colectivo de sector estatal, autonómico o provincial aplicable a este colectivo. Y es aquí donde se echa en falta la política proactiva que se exige en el Convenio 189 de la OIT (arts. 3.2.a) y 3.3) y en la Recomendación 201 de la OIT (disposición 2).

$\mathrm{Y}$ es que este Convenio asume que al igual que para el resto de las personas trabajadoras, su representación colectiva debe formar parte de un pilar fundamental en la defensa de sus intereses y en la integración de su normativa específica. En este sentido, recuerda el Convenio que

los convenios y las recomendaciones internacionales del trabajo se aplican a todos los trabajadores, incluidos los trabajadores domésticos, a menos que se disponga otra cosa.

Es más, cuando la regulación general necesite ser completada por normas específicas con el objeto de que las trabajadoras domésticas” puedan ejercer plenamente sus derechos”, esa intrusión normativa se hará consultando anteriormente 
con las organizaciones más representativas de los empleadores y de los trabajadores, así como con organizaciones representativas de los trabajadores domésticos y organizaciones representativas de los empleadores de los trabajadores domésticos, cuando tales organizaciones existan ${ }^{24}$.

El papel de la autonomía colectiva en esta relación laboral especial, por consiguiente, puede ayudar a completar la visión social de la sostenibilidad, del mismo modo que la regulación convencional del servicio doméstico es imprescindible para conocer sus derechos (MENENDEZ, 2020:33-58).

\subsection{El derecho de huelga como sistema de reacción}

El Decreto-ley 5/1975, de 22 de mayo, sobre regulación de los conflictos colectivos de trabajo, supuso una etapa importante en la evolución histórica de la legislación laboral, en cuanto que consagro la legitimidad del recurso a la huelga, siempre que se observaran los requisitos de fondo y de forma que el propio texto legal contenía.

Este derecho fundamental es un pilar básico en el sistema constitucional y en las relaciones laborales. Las nuevas formas de organización empresarial, como los grupos de empresas, así como la introducción y la incidencia de las nuevas tecnologías en el ámbito de la producción y organización empresarial han incitado a que se endurezca el derecho a la huelga como herramienta fundamental de las personas trabajadoras para la defensa de sus derechos en una sociedad globalizada y tecnológica.

El derecho de huelga es, sin duda, la herramienta de acción sindical más importante de la que disponemos las personas trabajadoras reconocido constitucionalmente y recogido en el apartado número 2 del artículo 28 de la Constitución Española: "Se reconoce el derecho a la huelga de los trabajadores para la defensa de sus intereses" 25 . No solo por la influencia que se ejerce a la empresa a fin de obtener un desenlace determinado, sino también por la consecuencia que ésta tiene en la sociedad (MERCADER, 2001:12).

El derecho de huelga, estamos al corriente, que se confía a los trabajadores en general, es decir, en razón de su posición social cualificada por su pertenencia en tanto prestadores de servicios para otro, en una situación de subordinación o de dependencia sea cual fuera la forma con arreglo a la cual se presente en la regulación jurídica específica. Trabajador o trabajadora como categoría general no necesariamente ligada a una relación contractual, a una relación de servicio o a la pertenencia a una empresa en concreto o a una dependencia administrativa.

\footnotetext{
24 Arts. 2.2 -exclusiones subjetivas-, art. 13.2 -seguridad y salud en el trabajo-, art. 14 -protección de Seguridad Social, incluida la maternidad-, 15.2 -abusos de las agencias privadas de empleo y en la contratación, colocación y el empleo-, art. 18 -cláusula general de aplicación del convenio mediante extensión, adaptación o establecimiento de medidas específicas para el sector-

${ }^{25}$ El derecho a huelga viene regulado en el artículo 28.2 de la Constitución española y desarrollado por el Real Decreto Ley de 4 de marzo de 1977, pero no aparece definido por ninguna de las dos normas, por ello el Tribunal Constitucional es su sentencia no 11/1981, de 8 de abril de 1981 define la huelga como "una perturbación que se produce en el normal desenvolvimiento de la vida social y en particular en el proceso de producción de bienes y de servicios que se lleva a cabo en forma pacífica y no violenta, mediante un concierto de los trabajadores y de los demás intervinientes en dicho proceso. En este sentido amplio, la huelga puede tener por objeto reivindicar mejoras en las condiciones económicas o en general en las condiciones de trabajo, y puede suponer también una protesta con repercusión en otras esferas o ámbitos, cuyo contenido esencial es la cesación del trabajo en la relación contractual.”.
} 
Las razones por ende de la especialidad de esta relación laboral, que como hemos reiterado, consisten fundamentalmente en el lugar de desempeño del trabajo y en la consiguiente conexión con los derechos fundamentales de la parte empleadora, como son la inviolabilidad del domicilio y el derecho a la intimidad personal y familiar, podrían justificar limitaciones del ejercicio de algunos derechos colectivos, como puedan ser el derecho de huelga, o los derechos de información, que de extenderse a esta relación podrían quebrantar el derecho a la intimidad de la parte empleadora.

Recapitulando, las empleadas del hogar claro que tienen derecho al ejercicio del derecho a la huelga, pero al tratarse de un derecho de titularidad individual, pero de ejercicio colectivo, significa que para que una huelga sea efectiva, hará falta el consenso del resto de personas trabajadoras, aquí encontramos el primer obstáculo para el colectivo del trabajo doméstico, ya que una huelga de una persona no es legal y se vería como un incumplimiento del contrato.

Y es que el ejercicio del derecho de huelga, como medida de fuerza que supone la paralización del trabajo, produciría desconfianza entre las partes, haciendo desistir de la relación laboral al empleador sin necesidad de justificación alguna (NIETO, 2019:397410), al tratarse de un régimen laboral especial, la relación se basa en la confianza teniendo la parte empleadora el poder de romper la relación sin dar ningún motivo (desistimiento) o simplemente utilizando como justificación el incumplimiento de contrato como hemos advertido ya, por lo que no lo ponen en práctica estas mujeres trabajadoras.

$\mathrm{Y}$ en el supuesto de que reclame contra el desistimiento del empresario que, no debemos olvidar, es el instrumento que se le ofrece para romper una relación laboral cuando existe esa pérdida de confianza sin necesidad de tener que probarla, tal desistimiento podría calificarse como nulo por contravenir el derecho fundamental de huelga, ya que como consecuencia del ejercicio del mismo no puede haber sanción por parte del empleador, así lo establece el Artículo 6 del Real Decreto Ley 4 de marzo de 1977, según el cual

el ejercicio del derecho de huelga no extingue la relación de trabajo, ni puede dar lugar a sanción alguna, salvo que el trabajador, durante la misma, incurriera en falta laboral.

Pero en caso que nos ocupa, si se declararse la nulidad del desistimiento la relación laboral tendría que continuar, con lo que aumentaría la pérdida de confianza mutua, característica de esta relación especial, forzándose una convivencia definida como “infierno sartriano” (PEDRAJAS, 1992:183).

\subsection{La exclusión de la protección del Fondo de Garantía Salarial}

Otra gran diferencia con el resto de personas trabajadoras, es estar excluida la relación especial doméstica de la cotización y protección a cargo del Fondo de Garantía salarial (en adelante FOGASA), que como sabemos es un organismo autónomo adscrito al Ministerio de Trabajo y Economía Social, que se financia con fondos públicos y con aportaciones empresariales, y es el pagador de los salarios e indemnizaciones de las personas trabajadoras, ante la insolvencia de la empresa ya sea por causa de despido, de extinción de la relación laboral, o por impago de salarios, pendientes de ser abonados a causa de insolvencia o concurso de acreedores del empresario . Del mismo modo, abonará indemnizaciones reconocidas como consecuencia de sentencia, auto, acto de conciliación 
judicial o resolución administrativa a favor de las personas trabajadoras a causa de despido o extinción de los contratos conforme a los arts. 50, 51, 52, 40.1 y 41.3 del ET

El Gobierno es el encargado de fijar el tipo de cotización sobre los salarios que sirven de base para el cálculo de la cotización correspondiente a las contingencias de accidentes de trabajo, enfermedad profesional y desempleo en el sistema de la Seguridad Social. No obstante, en este Sistema Especial la cotización se limita a los conceptos de contingencias comunes y profesionales, sin que el proceso de convergencia con el Sistema General avanzara en este punto; de manera que no se prevé la cotización para este colectivo por los conceptos de recaudación conjunta, como la formación profesional, quedando excluido del catálogo de prestaciones el desempleo. Del mismo modo que tampoco se les extiende la acción protectora del FOGASA.

La exclusión de la cotización por parte de la persona empleadora de la protección a cargo del FOGASA es conforme a la Directiva del Consejo de 20 de octubre de 1980, sobre la aproximación de las legislaciones de los Estados miembros relativas a la protección de los trabajadores asalariados en caso de insolvencia del empresario (80/987/CEE, DO L 283, de 28 de octubre de 1980), que en su Anexo (modificado por la Directiva del Consejo de 2 de marzo de 1987, 87/164/CEE, DO L 66, de 11 de marzo de 1987) señala a los “domésticos al servicio de una persona física” de nuestro país como categoría de trabajadores asalariados que tienen un contrato de trabajo o una relación laboral de carácter particular "cuyos créditos pueden excluirse del ámbito de aplicación de la Directiva”.

Del mismo modo, en el art. 3 del RLESHF, se dispone como hemos indicado ya, que los derechos y obligaciones que conciernen a esta relación laboral de carácter especial se regularán, por las disposiciones contempladas en el ET con carácter supletorio, en lo que resulte compatible con las peculiaridades derivadas del carácter especial de esta relación. Por tanto, expresamente no será de aplicación el artículo 33 del ET que viene a regular el FOGASA y que no será de aplicación en esta relación especial.

De esta forma, en lo concerniente al mismo, la nueva norma no introduce ningún tipo de mejora, por lo que en este ámbito no se produce ningún tipo de acercamiento con las relaciones laborales del régimen general, volviendo a quedar fuera del alcance del ámbito doméstico el acceso a estas prestaciones.

Por lo tanto, la trabajadora dedicada al servicio doméstico no puede reclamar la percepción de las cantidades salariales adeudadas ante el FOGASA, vulnerando esta excepción el art. 16 del Convenio 189 OIT (no ratificado por España), en el que se establece que los países miembros deberían adoptar medidas para asegurar que los trabajadores domésticos disfruten de condiciones que no sean menos favorables que las que se apliquen a los demás trabajadores en general en lo relativo a la protección de los créditos laborales en caso de insolvencia o de fallecimiento del empleador.

\section{Reflexiones finales}

En la sociedad actual, el trabajo doméstico resulta esencial para el funcionamiento productivo de nuestra economía, por lo que no se entiende que la invisibilidad, la precariedad, la irregularidad y la desprotección social de este trabajo sean características que afecta a este colectivo, altamente "feminizado".

La inclusión de las empleadas de hogar en el Régimen General de la Seguridad Social supone un avance importante en materia de protección social, con un progresivo 
acercamiento a la protección dispensada por este Régimen al resto de personas trabajadoras, lo que sin duda era necesario. Sin embargo, hay que seguir avanzando para lograr la equiparación plena con el resto de trabajadores/as por cuenta ajena ya que desde que se creó en 2012 sigue teniendo características propias que lo diferencian del Régimen General, con el que debía haberse equiparado plenamente el 1 de enero de 2019.

El reconocimiento de los derechos colectivos en la relación laboral especial del hogar familiar plantea fundamentalmente una cuestión de límites y en su caso de adaptación, en principio, a través de su normativa específica. No obstante, la inexistencia o, como mucho, la marginalidad, es la tónica general del tratamiento de los derechos colectivos en la regulación de las relaciones laborales especiales. Tal es así, que el RLESHF, no tiene ni una sola mención o tratamiento mínimo adaptativo ni de la representación unitaria, ni de la actividad sindical en la empresa, ni de los derechos de huelga, negociación colectiva y conflicto.

Efectivamente, parece que el RLESHF deja poca oportunidad a la negociación colectiva, cuando el régimen jurídico de esta relación laboral permite identificar espacios innegablemente abiertos a la negociación colectiva, como puedan ser la incorporación del régimen jurídico del desistimiento indemnizado de la persona trabajadora, o la integridad de la relación laboral, como son las tareas y la clasificación profesional, la jornada y el horario, retribuciones, permisos y licencias, la prevención de riesgos laborales, la prevención del acoso sexual, acoso por razón de sexo, el mobbing, la conciliación familiar entre otros.

La fuerza y el poder de los trabajadores/as del hogar para negociar unas condiciones de trabajo decente dependen en última instancia de su capacidad para organizarse y participar en acciones colectivas, pero los convenios colectivos en este ámbito carecen de relevancia ya que las trabajadoras están escasamente sindicadas y no existen asociaciones empresariales específicas pues, en realidad, el empleador no es un empresario mercantil, sino el titular de un hogar familiar, es por ello que este colectivo carece de sujetos legitimados para negociar convenios colectivos, lo que contribuye a que se sigan produciendo, en el ámbito del hogar familiar, distintas situaciones de abusos y precariedad.

El derecho de huelga sigue siendo el instrumento de presión más importante con el que cuentan las personas trabajadoras en situaciones de conflicto. En realidad, no existe una Ley de Huelga y, por tanto, es necesario acudir a la normativa laboral básica también en el caso de este colectivo, ajustándose a las normas del régimen general como eje de normativa laboral básica. Efectivamente, el derecho de huelga existe y pueden hacer uso de él las trabajadoras domésticas, pero la realidad ante la que nos encontramos es que la parte empleadora, sin la necesidad de indicar una causa, puede extinguir la relación laboral sin justificar.

El RLESHF considera, como hemos indicado, norma supletoria al ET, siempre que resulte compatible con las peculiaridades derivadas del carácter especial de esta relación laboral. Sin embargo, este Real Decreto excluye expresamente la aplicación del artículo $33 \mathrm{ET}$, por tanto, las empleadas de hogar no poseen las garantías que concede el FOGASA en caso de impago de salarios o indemnizaciones por insolvencia o concurso del empresario.

La lectura de la finalidad en el preámbulo del RLESHF, revela la influencia del Convenio 189 de la OIT adoptado por la Conferencia el 16 de junio de 2011, tan solo 
unos meses antes, por lo que supone que dicho Convenio, así como su Recomendación ya citados, son medidas de corte internacional destinada a mejorar las condiciones laborales de millones de trabajadores del sector. Supone un paso más en pos de la dignificación de las condiciones de trabajo de unos colectivos que arrojan unas cifras llamativas en cuestión de derechos laborales. Por lo que, sin duda alguna, la ratificación por España del Convenio 189 OIT, aunque por sí misma no obligaría a cambios normativos inmediatos, sí debería ser el pistoletazo de salida para establecer un programa de actuación, con compromisos políticos y presupuestarios, para abordar, en plazo razonable, la reforma en lo que sea necesario y su efectiva implementación, ya que hasta hoy, poco se ha hecho a pesar de que es un sector que desde hace tiempo está haciendo un trabajo importante y necesario para la sociedad.

En cualquier caso, consideramos que para que aflore el empleo sumergido en el sector, no es suficiente con hacer modificaciones normativas, sino que es necesario cambiar la visión que todos los implicados tenemos respecto del trabajo doméstico, y tomar conciencia de que nos encontramos ante un trabajador por cuenta ajena, con sus derechos y obligaciones.

\section{Bibliografía}

Alarcón Caracuel, M.R. (1995), “La autonomía colectiva: concepto, legitimación para negociar y eficacia de los acuerdos”, La reforma de la negociación colectiva, coords. M. R. Alarcón/S. del Rey, Marcial Pons, Madrid.

Albiol Montesinos, I. (1990), El sindicato en la empresa. Ed. Deusto,

Ariño Villarrolla, A. (2004), “Asociacionismo, ciudadanía y bienestar social”, Revista de sociología, N. 74.

Benavente Torres, M.I. (2021). Dificultades para la negociación colectiva en el ámbito de la relación laboral especial del trabajo al servicio del hogar familiar. Lex Social: Revista De Derechos Sociales, 11(1).

Benavente Torres, I. (2019), "Un aspecto jurídicamente problemático: la extinción de la relación laboral”, Lex Social, vol. 9, núm. 2.

Blasco Martín, E (2019), “Contribución especial: pequeño cuestionario para la acción sindical en el sector del trabajo doméstico”, Lex Social, vol. 9, núm. 2.

Carrasco, C., Borderías, C. y Torns, T. (2011). "El trabajo de cuidados. Historia, teoría y políticas”. Reis $\mathrm{n}^{\circ} 140$.

Castillo Alonso, J.J. (1998), A la búsqueda del trabajo perdido. Tecnos.

Cavas Martínez, F. (1994), “Diversificación versus uniformidad en el Derecho Español del Trabajo”, REDT, núm. 63.

Cordero Gordillo, V. (2014), La relación laboral especial del servicio del hogar familiar, Tirant lo Blanch, Valencia. núm. 7

Fernández López, M.F. “Libertad ideológica y prestación de servicios”, RL, 1985,

García López, R., "Extinción del contrato del empleado de hogar: desistimiento, despido y fuerza mayor”, $A L, 1987$, tomo II. 
García Testal, E. (2019), "La extinción del contrato de trabajo de los trabajadores domésticos en España: un régimen jurídico injustificadamente diferenciado”, Lex Social, vol. 9, núm. 2.

Grau Pineda, C. (2019), “De sirvientas a trabajadoras: la necesaria ratificación del Convenio 189 OIT sobre trabajo decente para las trabajadoras y los trabajadores domésticos”, Lex Social, vol. 9, núm. 2.

López Gandía, J. y Toscani Giménez, D. (2012), El nuevo régimen laboral y de Seguridad Social de los trabajadores al servicio del hogar familiar, Bomarzo, Albacete.

López Gandía, J. y Toscani Giménez, D. (2006), Los trabajadores al servicio del hogar familiar. Aspectos laborales y de seguridad social. Propuestas de reforma. Bomarzo, Albacete.

Llorens Espada, J. (2020), "La extinción del contrato de trabajo doméstico: despido y desistimiento" en Reflexiones sobre el empleo doméstico: De dónde venimos, dónde nos encontramos y hacia dónde vamos. Gobierno Vasco. Bilbao.

Martínez Veiga, U. (1995), Mujer, trabajo y domicilio. Icaria. Barcelona.

Menéndez Calvo, R. (2020), "Regulación convencional del servicio doméstico, imprescindible para conocer sus derechos". Reflexiones sobre el empleo doméstico: De dónde venimos, dónde nos encontramos y hacia dónde vamos. Gobierno Vasco. Bilbao.

Mercader Uguina, J. R. (2001), "Derechos fundamentales de los Trabajadores y nuevas tecnologíasn ¿Hacia una empresa panóptica?”. Relaciones Laborales, núm. 10.

Monereo Pérez, J. L. (2002), Comentarios a la Constitución socio-económica de España, Comares.

Montoya Melgar, A., Galiana Moreno, J.M., Sempere Navarro, A.V. y Rios Salmerón, B. (2000), Comentarios al Estatuto de los Trabajadores, Aranzadi, Pamplona.

Moreno Vida, M.N. (1998), “Artículo 2. Relaciones laborales de carácter especial”, en Comentarios al Estatuto de los Trabajadores, Comares, Granada.

Navarro Nieto, F. (1993), La representatividad sindical, MTSS, Madrid.

Nieto Rojas, P. (2019), “Trabajo doméstico y derechos colectivos. Algunas reflexiones al hilo del RD. 1620/2011 y del Convenio 189 OIT”, Lex Social, vol. 9, núm. 2.

Olarte Encabo, S., "Legitimación representativa en la negociación colectiva: reglas legales en el marco de cambio de modelo”. Temas Laborales núm. 120/2013.

Ojeda Avilés, A. (1988), "Encuadramiento profesional y ámbito del Derecho del Trabajo”, Relaciones Laborales, tomo I.

Ojeda Avilés, A(1990), "Las relaciones laborales especiales: una perspectiva unitaria”, Relaciones Laborales, tomo I.

Panizo Robles, J.A. (2013), "La cobertura sociolaboral de las personas trabajadoras al servicio del hogar familiar". Informe para el Proyecto Promoting Integration of Migrant Domestic Workers in Europe. Madrid. 
Pedrajas Moreno, A. (1992), Despido y derechos fundamentales Estudio especial de la presunción de inocencia. Trotta.

Quesada Segura, R. (1991), El contrato de servicio doméstico, La Ley, Madrid.

Sala Franco, T. (1986), "La relación laboral especial del Servicio del Hogar Familiar y el contrato de trabajo doméstico”, $R L$, Tomo I.

Sanz Sáez, C. (2021), "Derechos colectivos y empleadas del hogar: reformas jurídicas inaplazables para un trabajo decente del trabajo doméstico en España”. Congreso Interuniversitario OIT sobre el futuro del trabajo (2019. Sevilla) Universidad de Sevilla. Facultad de Ciencias del Trabajo otros (aut.), Judith Carreras Garcia (comp.), Sabrina Haboba (comp.), Julieta Lobato (comp.), Vol. 1.

Vallés, M. (2007), Ciencia política; Una introducción, Ariel. 